\title{
Obstetric critical care services in South Africa
}

\author{
E C Buga, MB ChB, FCOG (SA); G D Nethathe, MB ChB, DA (SA), MMed (Anaes), FCA (SA), Cert Critical Care (SA); \\ L R Mathivha, MB ChB, FCPaed (SA) Critical Care, DBS (BM)
}

Intensive Care Unit, Chris Hani Baragwanath Academic Hospital, and Division of Critical Care, Faculty of Health Sciences, University of the Witwatersrand, Johannesburg, South Africa

Corresponding author: G Nethathe (gladness.nethathe@wits.ac.za)

More than half of all global maternal deaths occur in Africa. A large percentage of these deaths are preventable, and lack of access to adequate critical care facilities is a contributing factor. There are limited published data on the clinical and management challenges presented by the critically ill obstetric patient admitted to the intensive care unit in our setting, and more data are required in order to better define the critical care needs of this group of patients.

S Afr J Obstet Gynaecol 2015;21(1):4-5. DOI:10.7196/SAJOG.954

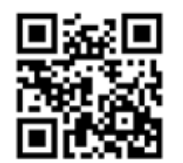

The critically ill obstetric patient presents many management challenges to the treating physician. When managing these patients, consideration needs to be given to the unique physiological changes that are associated with pregnancy, the wellbeing of the fetus, and the rapidity of reversal of many of these changes. The intensive care management of these patients can be complex and requires timeously instituted management from a multidisciplinary team consisting of intensivists, anaesthesiologists, physicians and obstetricians, among others.

Although obstetric conditions account for 55 - 80\% of intensive care unit (ICU) admissions of obstetric patients, medical conditions are now increasingly contributing to maternal morbidity and mortality. ${ }^{[1]}$ This is attributed to a number of factors, such as improved medical care leading to more women with severe medical conditions surviving and reaching child-bearing age, older age at the time of their first pregnancy, and assisted reproductive technology that has made it possible for women with chronic medical illnesses to conceive. The physiological changes of pregnancy may also exacerbate or mask severe medical conditions. ${ }^{[2]}$

More than half of all global maternal deaths occur in Africa. ${ }^{[3]}$ According to the United Nations data monitoring committee on maternal mortality, sub-Saharan Africa has the highest maternal mortality rate of 570/100 000 live births. ${ }^{[3]}$ Few if any countries in sub-Saharan Africa are in a position to meet the Millennium Development Goal of reducing maternal mortality by three-quarters by 2015. This applies to South Africa (SA) as well. According to the Committee on the Confidential Enquiry into Maternal Deaths (CEMD) in SA, the five major causes of maternal death in the period 2008 - 2010 were non-pregnancy-related infections/AIDS, accounting for $40.5 \%$ of all deaths reported; obstetric haemorrhage (14.1\%); hypertensive disorders (14\%); medical and surgical disorders (8.8\%); and pregnancy-related sepsis (5.3\%). ${ }^{[4]}$

A large percentage of these deaths were preventable, with patient-related factors contributing to $49 \%$ and health systems and healthcare worker-associated factors making up 35\% of the avoidable factors leading to maternal deaths. The problems associated with health systems included failure of ambulance transport between levels of care, unavailability of blood and blood products, inadequate staff numbers and lack of access to ICUs. Healthcare worker-associated problems related to lack of

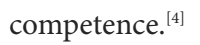

The situation is not very different in the First-World setting. Recent reviews of maternal mortality in the USA, France and the UK suggest that $40-50 \%$ of maternal deaths are preventable. ${ }^{[5]}$ This prompted the National Partnership for Maternal Safety to propose an obstetric early-warning system to identify those patients who develop clinical signs of critical or life-threatening illness so that necessary interventions can be instituted.

Retrospective heterogeneous data on critically ill obstetric patients are available, and highlight some aspects that may not necessarily apply to our setting; many of these studies are from well-resourced settings.

Kilpatrick and Matthay ${ }^{[6]}$ in 1992 published a 5-year review of obstetric admissions to the ICU at the University of California, USA, and showed respiratory and haemodynamic instability to be the main reasons for admission. The overall rate of ICU admission of $0.4 \%$ was due to the main ICU being a distance from their obstetric unit. Bed availability and triage criteria dictated how many patients were admitted.

Zwart et al. ${ }^{[7]}$ in 2009 carried out a 2-year nationwide populationbased cohort study on the incidence of and risk factors for obstetric intensive care admissions in the Netherlands. The overall incidence of admission of obstetric patients to the ICU in the Netherlands was $0.24 \%$. Severe obstetric haemorrhage, hypertension and sepsis were the most common reasons for admissions. A third of patients with severe acute maternal morbidity (SAMM) were admitted, making ICU admission a good measure of the management of patients with SAMM in that setting. ${ }^{[7]}$

The term SAMM, also referred to as a 'near miss', refers to a woman who has severe organ dysfunction or failure in pregnancy, childbirth or within 42 days of termination of pregnancy that could result in maternal death, but survives. ${ }^{[8]}$ SAMM is used to judge the quality of maternal healthcare in instances where the maternal mortality statistics are low.

In a prospective review done by Wanderer et al. ${ }^{[9]}$ in Maryland, USA, the overall rate of ICU admissions was 419.1/100 000 deliveries. Most admissions occurred ante partum. The leading 
reasons for ICU admission were hypertensive diseases, cardiomyopathy and haemorrhage. A rising rate of sepsis was also noted. The researchers recommended that hospitals caring for pregnant women should plan for appropriate critical care management and/or transfer of women with severe morbidity during pregnancy.

The studies mentioned above also show a homology with the SA setting, where haemorrhage, hypertension and sepsis are the leading reasons for admission of obstetric patients to the ICU.

The required resources for the intensive management of these patients also seem to differ depending on the setting.

A retrospective observational report from Australia by Paxton et al. ${ }^{[10]}$ showed that, of the obstetric patients who were admitted to the ICU, a substantial number did not receive interventions typical of other critically ill patients, such as mechanical ventilation or inotropes, raising the question of whether the low threshold of ICU admissions in some settings is appropriate. In contrast to the report from Australia, Ashraf et al., ${ }^{[11]}$ in a retrospective review of ICU admissions in a teaching hospital in India, showed that obstetric haemorrhage and hypertensive disorders were the most common reasons for ICU admission of obstetric patients. Eighty-five per cent of the patients required mechanical ventilation and $78 \%$ required inotropic support. There was a maternal mortality rate of $13 \%$ due to multiorgan failure and disseminated intravascular coagulation. The researchers showed that a dedicated obstetric ICU in a tertiary hospital can minimise delay in patient care and help reduce maternal mortality.

Chawla et al., ${ }^{[12]}$ in a study done in India, showed in a caseseries analysis of data that $0.26 \%$ of obstetric patients required ICU admission. Forty-six per cent of the patients admitted to an ICU required ventilatory support, with pre-eclampsia and obstetric haemorrhage being the commonest diagnoses in these patients.

These studies highlight the great demand for obstetric critical care services in areas with a high maternal mortality rate and perhaps the over-utilisation of these services in well-resourced centres in countries with a low maternal mortality rate.
Although the demand for critical care for obstetric patients is high, in SA there are only two dedicated obstetric ICUs in the public health sector, both in the Western Cape Province. One is attached to the Department of Obstetrics and Gynaecology of the University of Cape Town, and the other is at Tygerberg Hospital, in the Department of Obstetrics and Gynaecology, Stellenbosch University.

In addition there are no published data on the clinical challenges presented by critically ill obstetric patients in our setting, in particular with reference to the indications for admission, their clinical characteristics, organ support interventions required, and maternal mortality. Few if any studies in our setting have reviewed the incidence, possible risk factors and characteristics of obstetric patients admitted to the ICU. There is therefore a need to better describe the critical care needs of critically ill obstetric patients, as well as to highlight the need for establishing well-equipped, well-staffed high-dependency and dedicated obstetric critical care service units in the public sector.

1. Karnad DR, Lapsia V, Krishman A, et al. Prognostic factors in obstetric patients admitted to an Indian intensive care unit. Crit Care Med 2004;32(6):1294-1299. [http://dx.doi.org/10.1097/01. ccm.0000128549.72276.00]

2. Kaaja RJ, Greer IA. Manifestations of chronic disease during pregnancy. JAMA 2005;294(21):27512757. [http://dx.doi.org/10.1001/jama.294.21.2751]

3. UNICEF Data: Monitoring the situation of children and women. http://data.unicef.org/maternalhealth/maternal-mortality (accessed 6 December 2014).

4. Moodley J, Pattinson RC, Fawcus S, et al. The confidential enquiry into maternal deaths in South Africa: A case study. BJOG 2014;121(S4):53-60. [http://dx.doi.org/10.1111/1471-0528.12869]

5. Mhyre JM, Doria R, Hameed A, et al. The maternal early warning criteria. Obstet Gynecol 2014;124(4):782-786. [http://dx.doi.org/10.1097/aog.0000000000000480]

6. Kilpatrick SJ, Matthay AM. Obstetric patients requiring critical care: A five-year review. Chest 1992;101(5):1407-1414. [http://dx.doi.org/10.1378/chest.101.5.1407]

7. Zwart JJ, Dupuis JRO, Richters A, Öry F, van Roosmalen J. Obstetric intensive care unit admission: A 2-year nationwide population-based cohort study. Intensive Care Med 2010;36(2):256-263. A 2-year nationwide population-based cohor
[http://dx.doi.org/10.1007/s00134-009-1707-x]

8. Cochet L, Pattinson RC, Macdonald AP. Severe acute maternal morbidity and maternal death audit - a rapid diagnostic tool for evaluating maternal care. S Afr Med J 2003;93(9):700-702.

9. Wanderer JP, Leffert LR, Mhyre JM, et al. Epidemiology of obstetric-related intensive care unit admissions in Maryland: 1999-2008. Crit Care Med 2013;41(8):1844-1852. [http://dx.doi org/10.1097/ccm.0b013e31828a3e24]

10. Paxton JL, Presneill J, Aitken L. Characteristics of obstetric patients referred to an intensive care in an Australian tertiary hospital. Aust NZ Obstet Gynecol 2014;54(5):445-449. [http://dx.doi. org/10.1111/ajo.12211]

11. Ashraf N, Mishra SK, Kundra P, et al. Obstetric patients requiring intensive care: A one year retrospective study in a tertiary institute in India. Anesthesiol Res Pract 2014(2014):789450. [http://dx.doi.org/10.1155/2014/789450]

12. Chawla S, Nakra M, Mohan S, et al. Why do obstetric patients go to the ICU? A 3-year study. Med I Armed Forces India 2013;69(2):134-137. [http://dx.doi.org/10.1016.mjafi.2012.08.033] 